\title{
Analytical Procedure Detection Limit
}

National Cancer Institute

\section{Source}

National Cancer Institute. Analytical Procedure Detection Limit. NCI Thesaurus. Code C134244.

The lowest amount of analyte in a sample which can be detected but not necessarily quantitated as an exact value. 